\title{
Tension pneumoperitoneum
}

\author{
Giovanni Ferrara, ${ }^{1}$ Venkata Satish Kolli, ${ }^{2}$ Stefan Arnaudov, ${ }^{2}$ Graham Whiteley ${ }^{2}$
}

'Department of Anaesthetics, Betsi Cadwaladr University Health Board, Bangor, UK ${ }^{2}$ Department of Surgery, Betsi Cadwaladr University Health Board, Bangor, UK

Correspondence to Dr Giovanni Ferrara, giovanni.ferrara@wales.nhs.uk

Accepted 22 December 2017

Check for updates

To cite: Ferrara G, Kolli VS, Arnaudov S, et al. BMJ Case Rep Published Online First: [please include Day Month Year]. doi:10.1136/bcr-2017223069

\section{SUMMARY}

A 35-year-old man stopped breathing after injecting a large dose of heroin. He subsequently received cardiopulmonary resuscitation from friends. He arrived to accident and emergency department with Glasgow Coma Scale of 13. On examination, he had distended and tense abdomen. CT Thorax, Abdomen, and Pelvis confirmed massive tension pneumoperitoneum. A $14 \mathrm{Fr}$ intravenous cannula was inserted through the umbilicus to relieve the intra-abdominal pressure. An emergency laparotomy showed petechia along the anterior gastric wall, haematoma of lesser omentum but showed no evidence of gastrointestinal perforation or organ injury. Air leak test performed by insufflating air into the stomach via nasogastric tube and abdomen filled with normal saline showed no leak. On-table oesophagogastroduodenoscopy showed mild oesophagitis and petechia of cardiac gastric mucosa. He was treated with intravenous antibiotics and discharged on the fifth postoperative day with adequate analgesia.

\section{BACKGROUND}

Pneumoperitoneum is defined as the presence of free air in the peritoneal cavity usually due to the perforation of a hollow viscera of the abdomen. ${ }^{1}$ Patients presenting with an acute abdomen secondary to pneumoperitoneum are considered a surgical emergency; they usually warrant an exploratory laparotomy to identify the source of the free air. ${ }^{1}$ We report the case of a young man with tension pneumoperitoneum following cardiopulmonary resuscitation (CPR) from bystanders. Tension pneumoperitoneum is rare and can rapidly prove fatal unless the peritoneum is decompressed. This case report is important for junior doctors who may not be aware of the gravity of this finding, as it is not well covered in conventional textbooks.

$\mathrm{CPR}$ is a common intervention with proven benefits for the patient in respiratory or cardiac arrest. ${ }^{2}$ It is widely taught to lay people due to the benefits in prompt delivery of CPR. ${ }^{2-4}$ Common complications include rib fractures, sternal fracture, pulmonary injury, hepatic or splenic laceration, pneumothorax and gastric injury. ${ }^{2}$ Pneumoperitoneum is a rare complication of CPR and usually attributed to gastric injury or rupture. ${ }^{5}$ Spoormans et $a l^{4}$ reported a total of 67 cases of pneumoperitoneum using a Medline search up to August 2009, of which 11 were reported as tension pneumoperitoneum. ${ }^{4}$ They identified three risk factors for CPR-related gastric perforation: (1) bystander basic life support, (2) use of a bag mask and (3) difficult airway management. ${ }^{4}$

\section{CASE PRESENTATION}

A 35-year-old man was brought to the emergency department (ED) via an ambulance with decreased level of consciousness due to alleged overdose of heroin. His friends at the time started CPR. His Glasgow Coma Scale was 13 on arrival in the ED. He was short of breath and had a distended and tense abdomen.

His previous medical history includes attention-deficit hyperactivity disorder, self-harm, intravenous drug use, anaemia of unknown cause, alcohol abuse, seizures and depression. His social history includes lack of fixed abode, financial difficulties, unemployment and smoking. His medications include venlafaxine and suboxone.

\section{INVESTIGATIONS}

A CT scan demonstrated a massive pneumoperitoneum (figure 1), but the site of perforation was not identified.

\section{DIFFERENTIAL DIAGNOSIS}

Tension pneumoperitoneum.

\section{TREATMENT}

A $14 \mathrm{Fr}$ intravenous cannula was inserted through the umbilicus to relieve the pneumoperitoneum. An emergency laparotomy showed petechiae on the anterior gastric wall and haematoma of the lesser omentum. Gastro-oesophageal junction, small and large bowel up to rectum looked normal. An on-table oesophagogastroduodenoscopy showed no abnormality apart from mild oesophagitis.

$\mathrm{He}$ was given supportive treatment and was observed in the hospital for 5 days and discharged with regular analgesia.

\section{OUTCOME AND FOLLOW-UP}

- No postoperative complications.

- Discharged with follow-up in the clinic, which he did not attend.

\section{DISCUSSION}

CPR is a medical procedure used for resuscitation in cardiac arrest involving chest compressions and rescue breaths. ${ }^{5}{ }^{6}$ Common complications arise in 21\%-65\% of attempted CPR and include rib and sternal fractures, vomiting, pneumothorax and hydrothorax, cardiac contusion or laceration and hepatosplenic injuries. ${ }^{35}$ Gastric mucosal tearing occurs in $9 \%-12 \%$ of the cases ${ }^{245}$ and is considered a normal finding on autopsy in $10 \%-12 \%$ of cases of unsuccessful CPR. ${ }^{4}$ Gastric rupture, however, is a rare complication. ${ }^{257}$ Continuing to perform CPR 


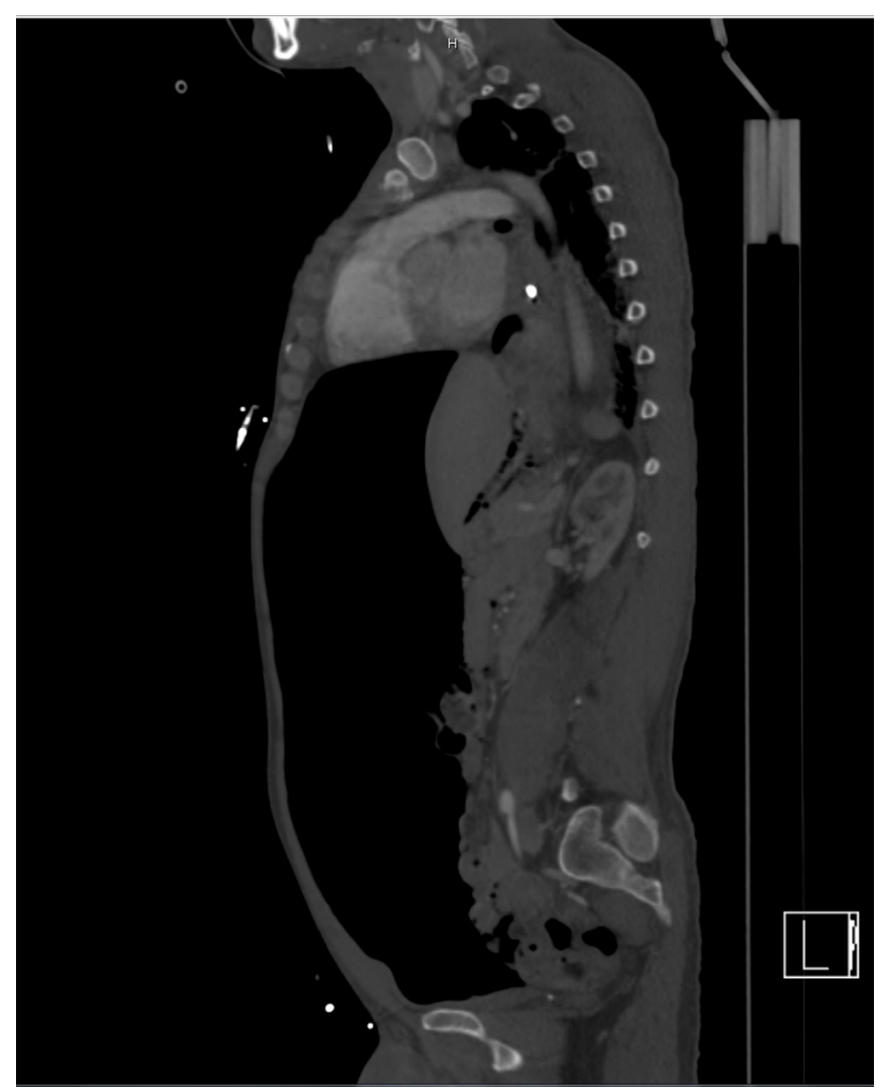

Figure 1 Trauma CT including abdomen and pelvis of a 35-yearold man. CT brain: no intracranial haemorrhage or mass effect, no calvarial fracture. CT thorax with contrast: no pneumothorax or obvious rib fractures, mild compression deformity of $\mathrm{T} 12$ vertebral body, no sternal fracture, subsegmental atelectasis in both lung fields, no significant lymphadenopathy, a small hiatal hernia is noted with mildly distended oesophagus. CT abdomen and pelvis with contrast: a massive pneumoperitoneum is seen, site of perforation could not be ascertained, no bowel wall thickening, the other abdominal viscera are unremarkable.

despite mucosal tears or gastric rupture is likely to cause pneumoperitoneum leading to tension pneumoperitoneum. ${ }^{3}$

Pneumoperitoneum is defined as the presence of free air in the peritoneal cavity. ${ }^{1}$ This is commonly due to a perforation of the hollow viscera, for example, perforation of the appendix, duodenal and gastric ulcers, a colonic diverticula and perforation of the bowel secondary to inflammatory bowel disease. ${ }^{148}$ The progression to tension pneumoperitoneum is a rare complication and is diagnosed by a grossly distended abdomen with signs of peritonism and respiratory distress. ${ }^{5}$ Spoormans et al reported 67 cases of pneumoperitoneum of which 10 were tension pneumoperitoneum. Five (of 10) cases were ascribed to a gastric rupture of the lesser curvature. ${ }^{4}$ Of all 67 cases of pneumoperitoneum following CPR, 41 cases were ascribed to rupture of the lesser curvature of the stomach including the tension pneumoperitoneum cases. ${ }^{4}$

Inadequate airway management is often an associated factor in the development of gastric rupture. ${ }^{2-5}$ Poor mouth-to-mouth technique, incorrectly sited endotracheal tubes and ineffective cricoid pressure increase the likelihood of inflating the stomach instead of the lungs. ${ }^{34}$ When intubating the stomach, a pressure of $120-150 \mathrm{~mm} \mathrm{Hg}$, the equivalent of $4 \mathrm{~L}$ of air, is thought to be enough to cause rupture of the stomach. ${ }^{245}$ The additional pressure exerted on the stomach by an inexperienced bystander performing CPR allows for higher pressure to be reached with lower gastric volumes. ${ }^{24}$ With increased pressure, it is difficult for the pylorus to empty ${ }^{4}$ and insufflation with air alters the gastro-oesophageal angle which prevents escape via the oesophagus. ${ }^{4}$ The lesser curvature of the stomach is the common site of tearing and perforation since it has fewer mucosal folds, hence, lower elasticity. ${ }^{2-4}$

Opiate abuse is also associated with an increased likelihood of gastric rupture. ${ }^{4}$ This is likely linked to the inhibitory effect opioids exhibit on antral motility or stimulation by opioids of the pyloric sphincter, effectively leading to gastroparesis. ${ }^{9}$

A chest radiograph may suffice to recognise pneumoperitoneum. ${ }^{1}$ Signs of pneumoperitoneum on radiograph include: air under the diaphragm, tenting of the right or bilateral hemidiaphragm, Rigler's sign and visualisation of the falciform ligament. ${ }^{1}$ Joshi and Ganai suggested key findings of tension pneumoperitoneum on CT; these include a compressed superior vena cava, marked elevation of the diaphragm and severely decreased thoracic volume. ${ }^{10}$ In tension pneumoperitoneum, delay in management while awaiting confirmatory imaging should be avoided. ${ }^{7}$ Furthermore, CT is not considered adequate to diagnose gastric perforation, ${ }^{2}$ but may find evidence of other causes of pneumoperitoneum. In the haemodynamically stable patient, direct visualisation by diagnostic laparotomy will show the cause(s) and permit immediate management. ${ }^{1-3}$

With increasing intra-abdominal pressure, venous return via the inferior vena cava will diminish and tenting of the diaphragm will compress the lungs. ${ }^{2}$ Further deterioration of the patient's condition may be prevented by nasogastric, orogastric or needle decompression-introduction of an intravenous cannula adjacent to the umbilicus to relieve the tension. ${ }^{237}$ In gastric rupture, surgical management involves debridement of edges and primary closure of the gastric wall defect as well as peritoneal washout and antibiotics. ${ }^{4}$ The remainder of the abdominal cavity must be explored to exclude further perforations. This may also help exclude other causes of pneumoperitoneum including iatrogenic, intrathoracic causes, sequelae of endoscopic evaluations, bladder rupture with indwelling urinary catheter and gynaecological procedures. ${ }^{178}$ Gastroscopy may be of additional diagnostic value. ${ }^{12}$

$\mathrm{CPR}$ is a life-saving intervention; nonetheless, tension pneumoperitoneum is a very rare and life-threatening complication.

\section{Learning points}

- Pneumoperitoneum is a very rare but grave complication of cardiopulmonary resuscitation.

- Tension pneumoperitoneum will compromise a patient's ability to breathe and diminish the venous return/preload.

- An intravenous cannula through the umbilicus may provide a temporary release of pressure to aid resuscitation.

- Tension pneumoperitoneum is an indication for emergency laparotomy and is commonly associated with gastric perforation along the lesser curve of the stomach.

Contributors GW conceived of the case report. GF, VSK and SA reviewed the literature. GF wrote the first draft and synthesis of the case report. All authors cared for the patient and contributed to refinement of the final manuscript.

Competing interests None declared.

Patient consent Obtained.

Provenance and peer review Not commissioned; externally peer reviewed. 
(c) BMJ Publishing Group Ltd (unless otherwise stated in the text of the article) 2018. All rights reserved. No commercial use is permitted unless otherwise expressly granted.

\section{REFERENCES}

1 T-I W, Tsai T-C, Chen P-J, et al. Spontaneous pneumoperitoneum: Report of one case. Acute Med 2013;3:20-2.

2 Offerman SR, Holmes JF, Wisner DH. Gastric rupture and massive pneumoperitoneum after bystander cardiopulmonary resuscitation. J Emerg Med 2001;21:137-9.

3 Mani VR, Pradhan L, Gray S. Development of pneumoperitoneum after CPR. Int I Surg Case Rep 2015;6C:40-2.

4 Spoormans I, Van Hoorenbeeck K, Balliu L, et al. Gastric perforation after cardiopulmonary resuscitation: review of the literature. Resuscitation2010;81:272-80.
5 Jalali SM, Emami-Razavi H, Mansouri A. Gastric perforation after cardiopulmonary resuscitation. Am J Emerg Med 2012;30:2091.e1-2091.e2.

6 British Heart Foundation. What is CPR - Cardiopulmoanry Resuscitation. 2017 https:// www.bhf.org.uk/heart-health/how-to-save-a-life/what-is-cpr (cited Jun 26 2017).

7 Ralston C, Clutton-Brock TH, Hutton P. Tension pneumoperitoneum. Intensive Care Med 1989;15:532-3.

8 Freitas Junior WR, Malheiros CA, Kassab P, et al. Idiopathic spontaneous pneumoperitoneum. Rev Assoc Med Bras 2011;57:600.

9 Camilleri M, Lembo A, Katzka DA. Opioids in Gastroenterology: Treating Adverse Effects and Creating Therapeutic Benefits. Clin Gastroenterol Hepatol 2017:15:1338-49.

10 Joshi D, Ganai B. Radiological features of tension pneumoperitoneum. BMJ Case Rep 2015:2015:bcr2015211148.

Copyright 2018 BMJ Publishing Group. All rights reserved. For permission to reuse any of this content visit http://group.bmj.com/group/rights-licensing/permissions.

BMJ Case Report Fellows may re-use this article for personal use and teaching without any further permission.

Become a Fellow of BMJ Case Reports today and you can:

- Submit as many cases as you like

- Enjoy fast sympathetic peer review and rapid publication of accepted articles

Access all the published articles

Re-use any of the published material for personal use and teaching without further permission

For information on Institutional Fellowships contact consortiasales@bmjgroup.com

Visit casereports.bmj.com for more articles like this and to become a Fellow 